\section{Development of School Laboratory Participation over a Period of Six Months: \\ A Case Study of Aspects of Divergent Thinking and Problem Discovery}

\author{
Swantje Müller iD \\ University of Oldenburg \\ swantje.mueller@uni-oldenburg.de \\ Verena Pietzner* iD \\ University of Oldenburg \\ verena.pietzner@uni-oldenburg.de
}

\section{Abstract}

Creativity, especially problem discovery and divergent thinking are skills that will be demanded for more and more jobs in the future. STEM subjects are leading the way. Schools are an important learning place to train the future generation of workers. However, promotion of creativity in STEM subjects is not sufficiently implemented. Chemistry teachers prefer frontal teaching instead of free, pupil-centered methods that encourage creative work. Extracurricular learning activities offer potential due to the free work atmosphere of a self-discovered problem. The creative way of working in the school laboratory is characterized by the fact that the participants find many different solutions to a problem and think divergently. Divergent thinking is a cognitive ability of a creative person in which different, divergent solutions are found to a problem. In the context of this study, the development of problem discovery and divergent thinking of gender, parental academic background and gender differences based on parental academic background will be presented in this study. It is based on two school laboratories: Agnes-Pockels Lab (without accompanying and professional support) and the DroPS project (with accompanying and professional support). Initial results show that School laboratory with accompanying and professional support offers a potential to participants problem discovery ability, especially boys and boys from non-academic parental backgrounds. Whereas no development of divergent thinking in both school laboratories could be found.

\section{Keywords}

Development, divergent thinking, extracurricular activities, free-choice learning, school laboratory, science education

- Received 01 September 2020 • Revised 05 January 2021 • Accepted 22 February 2021
State of the literature

- No studies exist so far addressing problem discovery and divergent thinking in school laboratories.

- Teachers see creative students as troublemakers (Westby \& Dawson, 1995). Children from socioeconomically disadvantaged families are disadvantaged in German school system (BMBF, 2019). - School laboratories offer the potential to work on scientific projects regardless of gender, relationship to teacher and socio-economic background.

\section{Contribution of this paper to the literature}

- This case study shows differences regarding problem discovery and divergent thinking between school pupils and participants at the beginning of the school laboratory and a development of problem discovery abilities.

- School laboratory with accompanying and professional support offers a potential to participants problem discovery ability, especially boys and boys from both academic and non-academic parental backgrounds.

- No development of divergent thinking in both school laboratories could be examined.

- Not the more creative pupils from academic parental backgrounds take part in Agnes-Pockels Lab or DroPS-Project. However, the more creative pupils from non-academic parental backgrounds take part in Agnes-Pockels Lab or DroPS-Project.

\section{Introduction}

According to the World Economic Forum's 'Future of Jobs' report (Gray, 2016), creativity will be one of the most important skills needed in professional life in the future. Creativity in science and technology is also fundamental to a progressive society, and schools play a vital role in teaching creative thinking to pupils. A report by the European Commission (2015) explicitly provides guidance for science teaching, with the aim of ensuring that scientific concepts learned in class enable pupils to be active and empowered citizens of the EU, who are able to critically advance problem-solving processes for the betterment of society. Nevertheless, promoting creativity is still not an essential part of school education in scientific fields such as chemistry, although it is prescribed in the curriculum (Niedersächisches Kultusministerium, 2017; Niedersächsisches Kultusministerium, 2012, 2015). In fact, experiments in chemistry classes are often conducted by pupils according to a strict set of instructions, with solutions often specified by stringent guidelines. Nevertheless, many teachers consider creativity an important skill, with $95 \%$ of teachers agreeing or strongly agreeing that creativity should be encouraged at school, and $70 \%$ agreeing or strongly agreeing that creativity can be taught to pupils (Cachia \& Ferrari, 2010).

Creativity in chemistry classes is important because it not only stimulates pupils' enjoyment of the subject but may also increase their interest in a scientific career (Starko, 2018). Teachers can promote creativity in chemistry classes by designing a self-determined, free learning atmosphere, which allows pupils to explore their own ideas (Semmler \& Pietzner, 2017). However, the free learning atmosphere required to develop creativity generally presents challenges to the most preferred teaching method, which is frontal teaching (Semmler \& Pietzner, 2017). A free learning 
atmosphere, however, might also be provided through extracurricular activities, such as school laboratories, where pupils have the opportunity to work freely on their own ideas, thereby promoting their interest in science alongside a more structured learning environment. School laboratories, as have been developed in the past decades, are very popular and have resulted in non-formal learning spaces (Council of Europe, 2003; Janštová, Dvořáková, \& Jáč, 2016). However, the value of extracurricular activities such as school laboratories has not yet been sufficiently investigated and, in particular, there is no research on the role of divergent thinking in these settings.

With respect to pupils' creativity, it is important that teachers stimulate divergent thinking and enhance their capability to have new experiences and explore the world. Divergent thinking is a very important ability, allowing individuals to better understand their experiences and form new connections, or see patterns emerge from a complex reality (Gajda, Jankowska, \& Karwowski, 2015). Such thinking is characteristic of creative individuals and is required in problem-solving processes in extracurricular activities generally (Urban, 2004; Wirt, 2011), and is not only important for problem-solving in science teaching. This element of divergent thinking and problem discovery in extracurricular activities is of specific interest in this paper, which focuses on the potential for the development of creativity over a school laboratory period of six months.

\section{Theoretical background}

Today, creativity is an important skill and will be even more so in the future, both in professional and private life. The OECD (2018) endorses this claim, arguing that by 2030, people should be able to think creatively, develop new products and services, new jobs, new processes and methods, new ways of thinking and living, new companies, new sectors, new business models and new social models. This means that the promotion of creativity in school is increasingly important. Divergent thinking plays a special role here.

According to Urban's 4P-E model (Urban, 2004), divergent thinking is an aspect of creativity which is related to the cognitive ability of a creative person. In brief, the $4 \mathrm{P}-\mathrm{E}$ model not only describes the problem-solving process, but also the entire interaction process between the person, problem, process and product, which is influenced, hindered or stimulated by the micro and macro environment (Urban, 2004). In this model, the creative person has three personality (1-3) and three cognitive (4-6) components:
(1) focus and task commitment,
(2) motivation and motives, and
(3) openness and tolerance of ambiguity;
(4) general knowledge and thinking base,
(5) specific knowledge base and area-specific skills, and
(6) divergent thinking and acting.

All six components work together in a creative person (Urban, 1991; Urban, 2004).

The main divergent thinking skills include problem sensitivity, fluency, flexibility and originality (Urban, 1991). The latter three are used as evaluation criteria in the test of divergent thinking in this study. In order to solve a problem divergently, a prerequisite for creative performance is the freedom to discover the problem, which must first be perceived sensitively (Runco \& Okuda, 1988; Urban, 2004). According to Runco and Okuda (1988, p. 212), 'Problem discovery is a particularly important component in the creative process because it occurs first, and because the quality of a problem may in part determine the quality of solutions. Therefore, problem discovery is crucial for all creative endeavours, across all domains (Runco \& Okuda, 1988).

Divergent thinking is an important component in the creative process. The term was first used by Guilford (1959), whose definition we use in this paper: 'In divergent thinking operations, we think in different directions, sometimes searching, sometimes seeking variety' (Guilford, 1959, p. 470). This is contrasted with convergent thinking, which often aims to develop one solution. Many creativity researchers have attempted to find ways to measure divergent thinking, with creativity tests not only developed by Guilford, the founder of modern creativity research, but also by creativity researchers such as Torrance, Wallach and Kogan, as well as Urban.

Creativity and its development present a broad field of research. Due to this broad scope, a uniform definition cannot be found. However, different models of creativity are widely accepted. One model developed by Kaufman and Beghetto (2009) categorizes and differentiates creativity into various levels and is known as the Four-C model, which will be used in this paper. The FourC model classifies creativity under: mini-c, little-c, Pro-C and Big-C. 'Mini-c' describes the transformative learning of an individual through the interpretation of experiences, actions and events; 'little-c' describes creativity in everyday life activities; 'Pro-C' is defined as the 'developmental and effortful progression beyond little-c' (Kaufman \& Beghetto, 2009, p. 5; not every person who works in a creative profession reaches the Pro- $\mathrm{C}$ category); and finally, 'Big-C' is defined as 'an eminent creator', who has a great impact on culture (Daniels, 2013; Kaufman \& Beghetto, 2009, p. 6). Sternberg (2018) states that it should not be presumed that individuals who are good in little-c are automatically good in Pro-C, while an individual with strengths in Pro-C does not necessarily become a Big-C.

The different levels of creative thinking and its development among school students are of particular interest to this study. Similar to the lack of a definition of creativity, there is also no general theory of creative development (Hemdan \& Kazem, 2019). Runco (2014) describes creative development as discontinuous, taking various forms in certain phases of life, primarily because creativity focuses on changes in conventionality. Based on Kohlberg's (1987) theory of moral development, young children are assigned to a preconventional stage, in which children neither know what conventions are, nor think according to these conventions (Runco, 2014). 
Understanding continues to develop in youth, when adolescents enter the conventional stage, where conventions are understood and applied (Runco, 2014). Since young children remain uninhibited about conventions, it is easier for them to act creatively. In contrast, originality is inhibited by conventions; thus, when an individual adheres to conventions it is difficult to be original (Runco \& Jaeger, 2012).

The development of creativity - more precisely, the process of discovering new creations - has also been found to depend on environmental stimulation (Cropley, 1978; Ribeiro Piske et al., 2017). To promote creativity in chemistry classes in school, teachers must create an environment of self-confidence and independence and ensure emotional and motivational conditions that stimulate individual thinking processes and reward original problem solutions (Cropley, 1978). However, it has also been found that teachers prefer frontal teaching methods and the use of set instructions to complete experiments in chemistry lessons. These do not promote creativity in the classroom, which is to the detriment of pupil-centred methods that give children the opportunity to develop, test and revise their own ideas (Gärtner, 1997; Kind \& Kind, 2007; Semmler \& Pietzner, 2017).

Extracurricular activities such as science competitions or school laboratories offer a special opportunity here, since participants can independently develop and work on solutions. This creates a stimulating environment, which furthers the development of creativity. In addition, participants may be required to choose or build the equipment they need to plan, develop, test and revise their solutions to their self-discovered problems. Participants become familiar with the methods used in school laboratories, where they can work freely on their own projects. According to Starko (2018), encouraging such methods may promote little-c activities and is an important dimension of such extracurricular activities. This can have a unique impact on motivation, which may increase when participants identify with the scientific learning community (Sahin, 2013). Moreover, participants can 'foster interpersonal competence, help define life goals, and promote educational success' (Wirt, 2011, p. 48).

Divergent thinking and problem-solving ability in chemistry education, as well as their possible development over a period of time, have been scientifically investigated. In this regard, the effect of parental academic background, which are at least one parent with tertiary degree, on divergent thinking and problem discovery skills of participants in school laboratories is particularly interesting. Smith and Carlsson (1985), for example, found a connection between parental academic background and creativity of pupils in middle and late school years. Runco (2014) also identified a connection between creativity, its development and parental education. No other studies with a focus on learning environments could be found.

It has been found that pupils with good grades are preferred in the selection process for science competitions in school because teachers see a connection between good grades and good performance at such competitions (Descalço \& Oliveira, 2018). Insofar as creative pupils tend to show character traits such as non-conformism, as well as risk-taking, idiosyncratic and uncontrolled behaviour, they are often perceived by teachers as 'troublemakers' rather than good pupils (Cropley, 1978; Westby \& Dawson, 1995; Wirt, 2011). In summary, studies of gender differences and the influence of parental academic background reveal that these factors may have an influence on participation in extracurricular activities such as science competitions, with more creative children, and specifically girls, taking part less often.

To date, the development of creativity in school laboratories - more specifically, problem discovery and divergent thinking with regard to parental academic background and gender - has been rarely examined. Only two publications on creativity in extracurricular activities could be found, with one publication investigating science competitions and the other investigating a school laboratory. Firstly, Mund (2007) measured the creative skills of participants in Germany's largest national science competition. In this study, participants in the Young Scientist Competition, Jugend forscht e. $V$., achieved higher results in the creativity test than the control group consisting of 464 students aged 15 to 21 from three Gymnasium in North Rhine Westphalia. Rather than using a divergent thinking test, this study used a graphic creativity test developed by Urban and Jellen (1993) to measure the holistic creative process.

Secondly, another study measured the development of creativity in a problem-based informal science setting, conducting a pilot study of a 12-week out-of-school intervention programme in Spain using the CREA-C test (Gómez, Toma, Ortiz-Revilla, \& Merino, 2019). This study found an increase in creativity in the process of learning physics. There are other isolated studies of formal physics learning environments from Asian countries such as China (Hu \& Adey, 2002), Korea (Jo, 2009) and Malaysia (Mohtar, Halim, \& Iksan, 2016), as well as from Kenya (Omusonga, Indoshi, \& Achieng'Rabari, 2011) and Greece (Diakidoy \& Constantinou, 2001).

This case study intends to close the research gap by addressing the following research questions:

1) Do divergent thinking and problem discovery differ between pupils who take part in DroPS project (with accompanying and professional support) and a control group in school?

2) Do divergent thinking and problem discovery develop due to the involvement in DroPS project over a period of six months?

3) Do divergent thinking and problem discovery differ between pupils who take part in a school laboratory such as the Agnes-Pockels Lab (without accompanying and professional support) and a control group in school?

4) Do divergent thinking and problem discovery develop due to involvement in a school laboratory such as the Agnes-Pockels Lab over a period of six months?

5) Can differences between the different groups be found regarding gender and parental academic background? 


\section{Instrument for creativity measurement}

Various tests have been developed since the beginning of creativity measurement. There are therefore many verbal and figural tests that are designed to measure creativity-relevant aspects. Probably the best-known figural creativity test is the Torrance (1966) Tests of Creative Thinking (TTCT), which is based on the types of tasks developed by Guilford for divergent thinking (Urban, 2011). Tests on divergent thinking are suitable for measurement of creative abilities and belong to the important area of creativity research (Silvia et al., 2008).

A well-known verbal test for measuring divergent thinking was developed by Wallach \& Kogan (1965), which is also based on Guilford's (1959) proposed theoretical model. Due to proven quality criterion of reliability, which is proven using American data (Acar \& Runco, 2012; Cropley \& Maslany, 1969; Runco \& Okuda, 1988), this test was carried out together with the problem discovery test by Wakefield (1985). Germany, like the USA, is part of a western industrial country, therefore the test instruments do not have to be adapted to Germany and can be used after being translated. In addition, Wallach \& Kogan's divergent thinking test (1965) shows a good intercultural construct validity (Storme, Lubart, Myszkowski, Cheung, Tong, \& Lau, 2017).

\section{Research design}

The research instruments for this case study were two adapted tests taken from Wallach and Kogan (1965) and Wakefield (1985). The first test contained presented problems, while the second test contained self-discovery problems. In the task section, 'Presented Problems', also called the divergent thinking test in our study, participants had to give answers in three different categories: instances, alternate uses and similarities. Here, the problems were already defined for each task. In the category of instances, the participants had to name various things - that are round, for example - or in the category of alternate uses they might have to list different ways to use a knife. In the task section, 'Discovered Problems', the participants had to define a task on their own and then provide solutions. The discovered problem test also used the three categories of instances, alternate uses and similarities (see Table 1).

The adaptation study by Runco and Okuda (1988) describes the evaluation method for the three criteria of fluency, flexibility and originality. 'Fluency' is described and evaluated as the number of ideas produced (Runco, 1986). 'Flexibility' is described as the number of categories from which ideas originate. To evaluate flexibility, all of the answers of the participants were assigned to a category based on Torrance's (1966) category list. This list was expanded with our own categories and group validated. The third criterion of 'originality' is described as statistical rarity of ideas. Originality was only measured in Wallach and Kogan's test (1965), not in Wakefield's problem discovery test (1985), because comparison of individually identified problems was not possible. Hence, the rarity percentage of the answer was used to assess originality (Runco \& Albert, 1985).
Table 1. Tests by Wallach and Kogan (1965) and Wakefield (1985).

\section{Adapted presented problem test (DT) by Wallach and Kogan (1965) \\ Adapted problem discovery test (PD) by Wakefield (1985)}

'Name all the round things you can think of', 'Name all the things you can think of that will make a noise',

'Name all the things you can think of that move on wheels'.
Alternate

uses

'Tell me all the different ways you could use a knife', 'Tell me all the different ways you could use a chair'.

'Tell me all the ways in which a potato and a carrot are alike', 'Tell me all the ways in which a cat and a mouse

Similarities are alike', 'Tell me all the ways in which a radio and a telephone are alike'.
'Choose a category, then list instances of it'.

'Choose an object then list uses for it'.

'Choose two objects that are alike, then list your ideas of how the objects are similar'.
A table with all of the answers was drawn up from each collection date for each survey learning location, allowing the frequencies of the answers given to emerge. An answer that was only given once received three points, answers that were given by two participants received two points, answers that were given by three participants received one point, and all of the other answers were not scored. For further calculation with SPSS, all mean values of the divergent thinking test for each criterion (fluency, flexibility and originality) were generated for all tasks in the categories of instances, alternate uses and similarities. In addition, mean values of all tasks were calculated for fluency and flexibility in the problem discovery test.

Both tests were incorporated into an app called Actionbound (2020), which was supported by the German Federal Agency of Civic Education. Using this app, participants could answer open questions on a keyboard and personal characteristics questions, such as parental academic background, by clicking on multiple-choice options. With the help of the app, the study could be conducted digitally and anonymously. The only requirement was a smartphone and a stable internet connection.

Before the data collection could be carried out, consent letters were sent to the participants of the school laboratory by mail, with the request to return them signed by their parents at the time of the data collection. In the case of a positive response to the invitation to participate in the study, the parents were asked to install the Actionbound app on their child's device. In order to be able to measure the development of the participants' divergent thinking in the student laboratories, the same test was carried out once at the beginning of participation and again after a six-month period. 


\section{Description of sample}

Twelve pupils involved in DroPS, three girls and nine boys (aged 16 to 18), participated in the study. The Agnes-Pockels Lab sample included 11 pupils aged 12 to 17, five girls and eight boys (see Table 2). Pupils in the control group from secondary schools in the Weser-Ems region included 56 girls and 48 boys, with six pupils not specifying a gender. The school pupils were 13 to 20 years old.

Table 2. Sample of main study.

\begin{tabular}{lccc}
\hline & DroPS & Agnes-Pockels Lab & School \\
\hline Female & 3 & 5 & 56 \\
Male & 9 & 6 & 48 \\
N/A & 0 & 0 & 6 \\
\hline Parental academic background & 7 & 9 & 55 \\
No parental academic background & 5 & 2 & 31 \\
\hline
\end{tabular}

Overall, the sample thus included adolescents aged 12 to 20 years, with the age range of the pupils from the Agnes-Pockels Lab and the school control group somewhat wider than the age range of pupils from DroPS (see Table 3).

Table 3. Age distribution in the sample.

\begin{tabular}{|c|c|c|c|c|c|c|c|c|}
\hline Gender $\quad$ Age in years & $12-13$ & 14 & 15 & 16 & 17 & 18 & 19 & $\begin{array}{l}20 \text { or } \\
\text { older }\end{array}$ \\
\hline Female participants & 6 & 1 & 2 & 5 & 1 & 0 & 0 & 1 \\
\hline Male participants & 3 & 3 & 2 & 1 & 1 & 1 & 0 & 1 \\
\hline N/A & 0 & 0 & 0 & 0 & 1 & 0 & 0 & 0 \\
\hline
\end{tabular}

\section{Pilot study}

For the pilot study, participants used the Actionbound app on their smartphone to complete Wallach and Kogan's divergent thinking test (1965) and Wakefield's problem discovery test (1985) during a 90-minute chemistry lesson. These tests were used in a study by Runco and Okuda (1988) and satisfy reliability criteria (Runco \& Okuda, 1988).

In addition to these two tests, the pilot study also used the figural circle test developed by Torrance (1966). Here, participants are asked to create as many figures or symbols as possible. The pilot study primarily concerned the testing of the feasibility of the app, as in the original studies by Wallach and Kogan (1965) and Wakefield (1985) the tests were administered in an interview setting, while Torrance's (1966) drawing test was completed with pencil and paper. For reasons of time, the drawing test was removed from the app.
The pilot study results for 16 female, 12 male and one participant with no defined gender, all from a German school, were downloaded from the Actionbound portal (for details regarding age, see Table 4.)

Table 4. Age and gender of pilot study participants.

\begin{tabular}{ccccccccc}
\hline Age in years & $12-13$ & 14 & 15 & 16 & 17 & 18 & 19 & 20 \\
\cline { 1 - 4 } Female participants & 6 & 1 & 2 & 5 & 1 & 0 & 0 & 1 \\
Male participants & 3 & 3 & 2 & 1 & 1 & 1 & 0 & 1 \\
\hline
\end{tabular}

\section{Main study}

To answer our research questions, we invited pupils involved in school laboratories and others who were not involved to participate in the study. The latter would be our control group, which consisted of German secondary school pupils in the Weser-Ems region. The pupils who were involved in school laboratories were also divided into two groups: one group was not given accompanying and professional support while working in the school laboratory, while the other group did receive support. Therefore, the results of the pupils from the two school laboratories were considered separately. The development of creativity in both lab groups was examined in terms of a general development without filtering the data, as well as regarding parental academic background and gender.

The first lab group attended the Agnes-Pockels Lab, with no accompanying and professional support, situated in Braunschweig, Lower Saxony and focus on chemistry. The Agnes-Pockels Lab was founded in summer 2003 (TU Braunschweig, 2020). Pupils voluntarily come to the laboratory for two hours on Thursday afternoons to work freely on their own projects using divergent thinking, in preparation for the Jugend forscht science competition, as well as working on experimental boxes with a total of 70 experiments for pupils of all ages using convergent thinking. The experiments in the boxes contain an instruction. Student assistants are present in the laboratory during their free working hours to ensure compliance with safety standards and provide materials. If the student assistants notice after several weeks that some groups are stagnating or are just doing show experiments for fun, they intervene and work together to find a solution. The fact that the student lab is voluntary, the students are not under pressure to find a solution to their problem quickly and decide themselves for which period they participate in the school lab.

The second lab group were involved in a pupil's project called DroPS (Drop Tower Project for School Students), initiated in 2004 by ZARM (Zentrum für angewandte Raumfahrttechnologie und Mikorgravitation; Centre for Applied Space Technology and Microgravity) at the University of Bremen, where pupils have a unique opportunity to work intensively on a scientific question 
and use a gravity-free space - or drop tower - to conduct their experiments. The second lab is limited to six months, so the school groups have to stick to this tight schedule. Although the drops project is open to all scientific disciplines, except for one chemical project, all the others were physical. The only chemical project dealt with the crystal growth of copper sulphate in weightlessness. The DroPS Project is carried out in cooperation with DLR_School_Lab (German Aerospace Centre) and Hackerspace e.V. The DLR_School_Lab is one of the largest and most modern research institutions in Europe (DLR, 2019), to which teams of pupils must apply in advance to have their project carried out in zero gravity. After approval of their project, teams meet regularly on the premises of ZARM, the Hackerspace and the DRL_School_Lab, and are involved in regular exchanges with supervisors in addition to work phases. The participating teams go through a total of four reviews during the process: a preliminary design review, a critical design review, an implementation progress review and a drop readiness review. In between reviews, there are continuous opportunities for work.

The first drop is carried out after week 16 on the premises of the DLR_School_Lab, using the facility's Space Tower (ZARM, 2018). Possible sources of error can be eliminated as a result, so that the new design can be tested again in a second drop after week 18 and a third drop after week 20. The final drop is conducted after week 21 in the ZARM drop tower, where the experiments are suspended for 4.74 seconds of weightlessness (DLR, 2019). A final presentation of the results of the experiment followed with each DroPS project ending after week 25.

\section{Data collection}

Data from a control group consisting of 110 pupils from German secondary schools was collected in spring 2018 before data were collected from pupils involved in the school laboratories. The provincial school authority gave approval for the study to collect data from pupils in different classes and different grades during a 90-minute chemistry lesson. Very few pupils failed to complete the tests within this timeframe, but those who did, not completed them later, using the app at home. Data from participants in the Agnes-Pockels Lab were collected twice: once at the beginning of the pupils' projects in January 2019, and again in June 2019 after they had been working in the lab for six months. Pupils participating in the DroPS project also completed the tests twice: once at the beginning of their DroPS project in January 2019 and a second time in June 2019 at the end of their project.

A U-test was used to visualize differences between pupils in the control group and pupils involved in the school laboratories. A U-test reveals differences in the central tendencies of two independent samples (Schwarz, 2020a).

A Wilcoxon test was used to determine the possible development of creativity in the school laboratory participants, focusing on their divergent thinking and problem discovery abilities. For this purpose, the average values of all categories (instances, alternate uses and similarities) for each criterion (originality, fluency and flexibility) from the first data collection date were compared to the average values of all categories for each criterion after six months. The Wilcoxon test indicates whether the central tendency of two dependent samples are different and is used if the requirements for a t-test are not met (Schwarz, 2020b). If the sample size is smaller than 30, an 'exact' setting is recommended (Schwarz, 2020b). To assess the significance of the results, effect sizes in the form of correlation coefficients are calculated and are divided by Cohen (1992). They can be described as follows: a strong effect of a U-Test is present at $r=0.50$, a medium effect at $r=0.30$ and a weak effect at $r=0.10$ (Schwarz, 2020a), while a strong effect of a Wilcoxon test is present at $r=0.40$, a medium effect at $r=0.25$ and a weak effect at $r=0.10$ (Schwarz, 2020b). In the following, findings with a significance level of up to less than 0.05 and a trend towards significance from 0.051 to 0.08 are reported.

\section{Results}

In this section, we will first present the results of the U-Test to identify differences between the control group and the Agnes-Pockels Lab, as well as between the control group and the DroPS project. The aim is to determine who actually takes advantage of extracurricular learning activities. Subsequently, we will present the results of the Wilcoxon test, measuring the possible development of creativity over a period of six months for the pupils involved in the AgnesPockels Lab (with no accompanying and professional support) and the DroPS project (with accompanying and professional support), considering differences related to parental academic background and gender, as well as gender with respect to parental academic background.

Differences between school pupil control group and DroPS participants An overall comparison of the two groups revealed differences regarding originality in the divergent thinking test and flexibility in the problem discovery test. DroPS participants scored higher on originality at the beginning of their project than the control group. However, the control group tended to perform better on flexibility in the problem discovery test than participants in DroPS (see Table 5).

Table 5. Differences between control group and DroPS participants.

\begin{tabular}{cccccccc}
\hline Test & Criterion & $\begin{array}{c}\text { Mean value } \\
\text { control (MVS) }\end{array}$ & $\begin{array}{c}\text { Mean value } \\
\text { DroPS (MVD) }\end{array}$ & $\boldsymbol{U}$ & $\boldsymbol{Z}$ & $\boldsymbol{p}$ & $\boldsymbol{r}$ \\
\hline $\begin{array}{c}\text { Divergent } \\
\text { thinking (DT) } \\
\begin{array}{c}\text { Problem } \\
\text { discovery (PD) }\end{array}\end{array}$ & Originality & 4.95 & 8.50 & 296,500 & -3.126 & 0.002 & 0.283 \\
\hline
\end{tabular}

Female DroPS participants significantly outperformed girls from the control group in originality on the divergent thinking test (see Table 6). 
Table 6. Differences between females of control group and DroPS project.

\begin{tabular}{cccccccc}
\hline Test & Criterion & $\begin{array}{c}\text { Mean value control } \\
\text { (MVS) }\end{array}$ & MVD & $\boldsymbol{U}$ & $\boldsymbol{Z}$ & $\boldsymbol{p}$ & $\boldsymbol{r}$ \\
\hline DT & Originality & 3,80 & 7,11 & 20,500 & -2.192 & 0.028 & 0.285 \\
\hline
\end{tabular}

Male DroPS participants tended to score better than the male controls on originality in the divergent thinking test (see Table 7).

Table 7. Differences between males of control group and DroPS project.

\begin{tabular}{cccccccc}
\hline Test & Criterion & $\begin{array}{c}\text { Mean value control } \\
\text { (MVS) }\end{array}$ & MVD & $\boldsymbol{U}$ & $\boldsymbol{Z}$ & $\boldsymbol{p}$ & $\boldsymbol{r}$ \\
\hline DT & Originality & 6,21 & 8,96 & 135,500 & $-1,773$ & 0.076 & 0.235 \\
\hline
\end{tabular}

DroPS participants without a parental academic background scored significantly higher on originality in the divergent thinking test than the school control group without a parental academic background (mean value DroPS first collection $=10.13$; mean value control $=4.30 ; \mathrm{U}=$ $24,000, \mathrm{Z}=-2.448, \mathrm{p}=0.014, \mathrm{r}=0.408$ ). Comparing both groups with a parental academic background, the school control group tended to be more flexible in the problem discovery test than the DroPS participants (mean value DroPS first collection $=2.10$; mean value control $=3.10$; $\mathrm{U}=107,000, \mathrm{Z}=-1.906, \mathrm{p}=0.057, \mathrm{r}=0.242)$.

\section{Development of DroPs participants}

Investigating the development of creativity over six months, the results showed that the DroPS participants improved on flexibility in the problem discovery test (mean value DroPS first collection $=2.28$; mean value DroPS second collection $=3.83 ; \mathrm{Z}=-2.363, \mathrm{p}=0.015, \mathrm{r}=0.682$ ). Overall, 11 DroPS participants performed better on flexibility after participation in the project, with only one showing a negative change. No significant development was measured by the divergent thinking test.

Regarding parental academic background and the potential development of divergent thinking and problem discovery, DroPS participants with a parental academic background showed no significant development in divergent thinking and problem discovery skills, while the skills of five DroPS participants without a parental academic background tended to be fostered (mean value DroPS first collection $=2.53$; mean value DroPS second collection $=3.80 ; \mathrm{Z}=-2.060, \mathrm{p}=0.063$, $\mathrm{r}=0.921)$.

With respect to gender differences in the development of divergent thinking and problem discovery abilities, no change was found in female DroPS participants, while for eight male DroPS participants, flexibility in the problem discovery test tended to be fostered over the course of their participation, and one showed a negative change (mean value DroPS male first collection
$=2.41 ;$ mean value DroPS male second collection $=3.67 ; \mathrm{Z}=-1.844, \mathrm{p}=0.070, \mathrm{r}=0.615)$. Four male DroPS participants without a parental academic background tended towards improvement on flexibility in the problem discovery test due to their participation over six months (mean value DroPS without first collection $=2.83$; mean value DroPS without second collection $=4.08 ; \mathrm{Z}=$ $-1.841, \mathrm{p}=0.066, \mathrm{r}=0.921)$.

\section{Differences between school pupil control group and Agnes-Pockels-Lab} participants

A comparison of the school pupil group with the Agnes-Pockels Lab participants also revealed differences. Participants in the Agnes-Pockels Lab performed significantly better than the control group on originality in the divergent thinking test at the beginning of their school laboratory involvement, while the control group significantly outperformed the Agnes-Pockels Lab participants on fluency and tended to score better on flexibility in the problem discovery test (see Table 8).

Table 8. School pupil differences between control group and Agnes-Pockels-Lab.

\begin{tabular}{cccccccc}
\hline Test & Criterion & $\begin{array}{c}\text { Mean value control } \\
\text { (MVS) }\end{array}$ & $\begin{array}{c}\text { Mean value APL } \\
\text { (MVA) }\end{array}$ & $\boldsymbol{U}$ & $\boldsymbol{Z}$ & $\boldsymbol{p}$ & $\boldsymbol{r}$ \\
\hline DT & Originality & 4.95 & 8.24 & 376,500 & -2.061 & 0.039 & 0.187 \\
\multirow{2}{*}{ PD } & Fluency & 4.78 & 3.03 & 357,500 & -2.234 & 0.025 & 0.203 \\
& Flexibility & 2.98 & 2.18 & 404,500 & -1.812 & 0.070 & 0.165 \\
\hline
\end{tabular}

Comparing differences between the control group and the Agnes-Pockels Lab participants according to gender, female participants in the Agnes-Pockels Lab outperformed the controls on originality in the divergent thinking test (mean value $A P L$ girls first collection $=8.00$; mean value control girls $=3.80 ; \mathrm{U}=47,500, \mathrm{Z}=-2.433, \mathrm{p}=0.015, \mathrm{r}=0.312$ No significant differences between the two groups of boys were found, nor were there any significant differences between the boys from the control group and the girls from the Agnes-Pockels Lab.

In addition, there were significant differences in certain aspects of creativity regarding parental academic background between the control group and Agnes-Pockels Lab participants at the beginning of the latter's involvement in the laboratory (first collection). School pupils with a parental academic background performed significantly better on fluency, and tended to be better on flexibility, in the problem discovery test than Agnes-Pockels Lab participants (see Table 9).

Table 9. Parental academic background differences between control group and Agnes-Pockels-Lab.

\begin{tabular}{cccccccc}
\hline Test & Criterion & MVS & MVA & $\boldsymbol{U}$ & $\boldsymbol{Z}$ & $\boldsymbol{p}$ & $\boldsymbol{r}$ \\
\hline \multirow{2}{*}{ PD } & Fluency & 5.00 & 2.78 & 117,000 & -2.523 & 0.012 & 0.320 \\
& Flexibility & 3.10 & 2.07 & 148,500 & -1.916 & 0.055 & 0.240 \\
\hline
\end{tabular}


For pupils without a parental academic background, the Agnes-Pockels Lab participants achieved significantly better results at the beginning of the school laboratory in the divergent thinking test on the criteria of fluency, and tended to score better on flexibility than the school pupil control group (see Table 10).

Table 10. No parental academic background differences between control group and Agnes-PockelsLab.

\begin{tabular}{cccccccc}
\hline Test & Criterion & MVS & MVA & $\boldsymbol{U}$ & $\boldsymbol{Z}$ & $\boldsymbol{p}$ & $\boldsymbol{r}$ \\
\hline \multirow{2}{*}{ DT } & Fluency & 5.82 & 11.00 & 7,000 & -1.812 & 0.070 & 0.315 \\
& Flexibility & 3.71 & 7.00 & 3,000 & -2.116 & 0.034 & 0.368 \\
\hline
\end{tabular}

\section{Development of Agnes-Pockels-Lab participants}

Comparing the data from the first and second collection points, no significant differences could be found to indicate development in originality, fluency and flexibility in divergent thinking or the development of fluency and flexibility in problem discovery over the six-month period. There were also no significant results in relation to differences in parental academic background.

\section{Discussion}

At the beginning of the DroPS project, participants involved in this extracurricular activity, which provided professional support, outperformed the school control group on some aspects of divergent thinking. Participants in the DroPS project scored higher on originality than the controls; however, they did not further improve this ability over the six months in which they worked on their DroPS project. Moreover, the school pupil control group scored significantly higher on flexibility in the problem discovery test than the DroPS participants.

In addition, we found a tendency development of flexibility in problem discovery in male DroPS participants, and, in particular, for boys without a parental academic background. Thus, the DroPS project appears to create a suitable environment for the development of a problem discovery ability, at least for boys. The precise correlations concerning the connection between this development and boys, especially boys without a parental academic background, must be investigated in further studies. However, this case study at least reveals some trends.

There was also some positive development in the case of the Agnes-Pockels Lab participants, which did not offer professional support. Participants in the Agnes-Pockels Lab performed better on some aspects of divergent thinking at the beginning of their work in the school laboratory and scored higher on originality compared to the school pupil control group, although the latter were stronger on problem discovery. The Agnes-Pockels Lab participants developed neither their divergent thinking nor their problem discovery ability over a period of six months. No developments dependent on gender or parental academic background were measurable.
In contrast, significant differences between the Agnes-Pockels Lab participants and the school control group were apparent even at the beginning of the former's lab participation. However, the differences in originality, which also occurred among DroPS participants, should be considered with caution, due to the different sample sizes of the two school laboratories and the statistical rarity of the answers (originality) within the learning groups. Comparing both groups in terms of parental academic background, the school control group performed significantly better than the Agnes-Pockels Lab participants on problem discovery. In contrast, comparing both groups in terms of no parental academic background, the Agnes-Pockels Lab participants outperformed the school control group on problem discovery.

The results of research questions 1 and 3, in which the student laboratory participants were compared with the control group, show that not the more creative pupils from academic parental backgrounds take part in Agnes-Pockels Lab or DroPS-Project. However, the more creative pupils from non-academic parental backgrounds take part in Agnes-Pockels Lab or DroPSProject. Extracurricular learning locations such as school laboratories seem to attract creative students with no parental-academic background, while the less creative with parental academic background take part in the extracurricular activities. One reason might be the conformity expected from teachers in schools. Conformity contradicts can even inhibit creativity. In school, teachers often see creative pupils as "troublemakers", as they often tend to have character traits such as non-conformity, willingness to take risks, wilfulness and uncontrollability (Cropley, 1978; Westby \& Dawson, 1995; Wirt, 2011). School laboratories offer the opportunity to conduct creative research on a scientific project regardless of the pupil's character traits and subjective perception. The fact that less creative students take more part in the student laboratory cannot be conclusively clarified based on the data available. Other studies also show an increased participation in math and science competitions of pupils with parental academic background as the pupils receive a high level of support through parents' intellectual resources (Stang, Urhahne, Nick, \& Parchmann, 2014). In other cultures, such as Taiwan, too, parents are increasingly encouraging an academic background their children in a science competition participate (Wu \& Chen, 1999).

In contrast to school, guided extracurricular activities such as the DroPS project seem to encourage boys from socioeconomically disadvantaged homes with respect to creativity, as seen in the results of research question 2. These findings contradict those of other studies, which found that children from higher socioeconomic backgrounds performed better on the verbal creativity test due to optimal development experiences (Barbot, et al., 2016; Miller \& Gerard, 1979). Parental behaviour and their parenting attitudes also have an impact on children's creativity. There may also be a connection between creativity development and parenting style, which should be examined in further studies. A cursory look at the literature indicates that parents have an influence on their children's creativity. For example, it has been found that parents of creative boys are less regimental, less critical and give their children a great deal of freedom (Datta 
\& Parloff, 1967). A study by Damian and Simonton (2015) hypothesized that poverty or early parental death can also be related to unconventional ideas. Moreover, using a test that was not based on verbal capabilities, as was done in this study, revealed creative skills among children without a parental academic background.

The issue of gender differences is a sensitive area that has not yet been comprehensively investigated. Half of all studies on creativity show no gender differences, while the other half show better results for females in a creativity test (Hemdan \& Kazem, 2019). This study found no gender differences, which might be considered positive, but this may also be the result of bias, as the number of girls who participated in this study was relatively low. It is also possible that the boys were more competitive and so dominated the group work, so that the girls, if they were present in the groups, were marginalized. Previous studies have found that boys are more dominant in groups, and that groups with a majority of boys tend to exclude girls (Gneezy, Niederle, \& Rustichini, 2003; Webb, 1984). For this reason, more research should be carried out in this area to come to reliable conclusions.

In the DroPS project, this downward trend in motivation was possibly counteracted. As suggested above, it is possible that the final drop experiment could have increased intrinsic motivation. However, this question must be investigated in further studies. Research question 2 , also requires further investigation, since there are no studies on DroPS learning location. While this study did not provide the data to support the assumption that creativity and learning go hand in hand, observations by the author agree with this claim by Hemdan and Kazem (2019). DroPS participants had to find ways and means for the best solution and had the constant goal of optimizing the experiment for the final drop. Beghetto (2019, p. 598) contradicts this hypothesis and postulates that creativity and the learning process are not interrelated but may be 'interdependent'.

Regarding experiments carried out in the student laboratories, solutions to everyday problems were often sought. A project, what should be mentioned here as an example is the crystal growth of copper sulphate in weightlessness in the DroPS project.

This project can be assigned to the little-c level. Nevertheless, unlike the Agnes-Pockels Lab, the DroPS project gave pupils an opportunity to develop aspects of their problem discovery ability and primarily promoted little-c. The participants examine a problem of their environment in the school laboratory, which, according to Urban's 4P E model, surrounds the four P's. The problem is approached with the participant's cognitive skills in the process and leads to the desired product. At DroPS, the participants were able to present a product after six months due to the given schedule. Due to the free and desired work phase in the Agnes-Pockels Lab, however, there is no time pressure, so that many respondents did not yet have a creative product. It is important to clarify whether all cognitive abilities that are required for the creative process have been activated or not.

\section{Limitations}

As mentioned briefly in the previous chapter, the interaction of the six components such as focus and task commitment, motivation and motives, and openness and tolerance of ambiguity; general knowledge and thinking base, specific knowledge base and area-specific skills, and divergent thinking and acting.

The cognitive changes in divergent thinking may also require more than six months to develop. As these results only reflect a tendency and must be discussed with caution due to the small sample size, a long-term study on a larger scale is still required to address this question and investigate whether divergent thinking stagnates or whether a temporal gap is present. Regarding the correlation between divergent thinking and time, according to Charles and Runco (2001), the question of other cognitive influences is relevant and thus should also be addressed in future studies.

Perhaps this is the reason why divergent thinking could not be developed. The motivation is certainly high in both student laboratories, but it is a privilege especially for the DroPS participants to take part in the project, as these participants have been carefully selected and have the unique opportunity to carry out their experiment in weightlessness.

In addition, further studies should be carried out in larger sample sizes.

While the results must be considered with caution due to the small sample size, they do receive an insight into the potential of different school laboratory approaches. The cause of the low number of girls should also be investigated in further studies.

\section{Conclusion}

This case study shows differences regarding problem discovery and divergent thinking between school pupils and participants at the beginning of the school laboratory and a development of problem discovery abilities. A school laboratory with accompanying and professional support offers a potential to participants problem discovery ability. DroPS participants, especially boys from both academic and non-academic parental backgrounds, can increase their problem discovery ability. No development of divergent thinking in both school laboratories could be identified. Moreover, not the more creative pupils from academic parental backgrounds take part in school laboratories like Agnes-Pockels Lab or DroPS-Project. However, the more creative pupils from non-academic parental backgrounds take part in Agnes-Pockels Lab or DroPSProject.

Further studies on the process and the interaction between the professional supervision in the school laboratory and the students should be carried out, to highlight which conditions and factors enable the development of the ability to cover problems. 


\section{Acknowledgements}

We want to thank Dr. Dirk Stiefs, head of the DLR_school_lab in Bremen, and Prof. Dr. Timm Wilke, former head of Agnes-Pockels-Lab for carry out the study in their school labs.

\section{Disclosure Statement}

The authors report no conflict of interest.

\section{References}

Abernathy, T. V., \& Vineyard, R. N. (2001). Academic Competitions in Science: What are the Rewards for Students? The Clearing House, 74(5), 269-276.

Actionbound. (2020). Schnitzeljagd-App. Smartphone-Rallye selber machen. [Scavenger Hunt App. Do your own Smartphone Rally]. de.actionbound.com

Andersson, A. L. (1984). Toward a Dialectical Conception of the Percept-Genetic Approach to Perception Personality. Psychological processes in cognition and personality, 125-134.

Baker, D., \& Leary, R. (1995). Letting Girls Speak out about Science. Journal of researcb in science teacbing, 32(1), 3-27.

Barbot, B., Lubart, T. I., \& Besançon, M. (2016). 'Peaks, Slumps, and Bumps': Individual Differences in the Development of Creativity in Children and Adolescents. In B. Barbot (Ed.), New directions for cbild and adolescent development. Perspectives on creativity developtment, 151, 33-45.

Beghetto, R. (2019). Creativity in Classrooms. In J. C. Kaufman \& R. J. Sternberg (Eds.), The Cambridge bandbook of creativity (Second Edition ed., pp. 587-606): Cambridge Cambridge University Press.

BMBF (2019). Bildung auf einen Blick 2019 - OECD Indikatoren. [Education at a glance 2019 - OECD indicators]. https://www.bmbf.de/files/6001821 mw.pdf

Cachia, R., \& Ferrari, A. (2010). Creativity in schools: A survey of teachers in Europe. Joint Research Centre (Seville site).

Charles, R. E., \& Runco, M. A. (2001). Developmental trends in the evaluative and divergent thinking of children. Creativity Research Journal, 13(3-4), 417-437.

Cohen, J. (1992). A power primer. Psychological Bulletin, 112(1), 155-159.

Commission, E. U. (2015). Science education for responsible citizenship. Luxembourg: EU-Commission.

Council of Europe. (2003). Non-formal education. https://rm.coe.int/2012-compendium-non-formaleducation $/ 168077 \mathrm{c} 10 \mathrm{~b}$

Cropley, A. J. (1978). Unterricht obne Schablone. Wege zur Kreativität. [Lessons Without a Template. Ways to Creativity]. Ravensburg: Otto Maier Verlag.

Damian, R. I., \& Simonton, D. K. (2015). Psychopathology, adversity, and creativity: Diversifying experiences in the development of eminent African Americans. Journal of Personality and Social Psychology, 108(4), 623.

Daniels, S. (2013). Facilitating creativity in the classroom: Professional development for K12 teachers. In M. B. Gregerson, J. Kaufman \& H. Snyder (Eds.), Teacbing creatively and teacbing creativity (pp. 3-14). New York: Springer.

Datta, L. E., \& Parloff, M. B. (1967). On the relevance of autonomy: Parent-child relationships and early scientific creativity. Proceedings of the 75 th Annual Convention of the American Psychological Association, 2, 149-150.

Descalço, L., \& Oliveira, P. (2018). Science Competitions: Do they foster learning? In EDULEARN18 Proceedings (pp. 1388-1394). Palma, Spain: Academic Press.

Diakidoy, I.-A. N., \& Constantinou, C. P. (2001). Creativity in Physics: Response Fluency and Task Specificity. Creativity Research Journal, 13(3-4), 401-410.

DLR (2019). DLR_school_lab Bremen. https://www.dlr.de/schoollab/desktopdefault.aspx/tabid-7605
Gajda, A., Jankowska, D., \& Karwowski, M. (2015). How to Develop Children's Creativity and Intercultural Sensitivity: Around Creativity Compass Program. In A.-G. Tan \& C. Perleth (Eds.), Creativity, Culture, and Development (pp. 133-145). Singapore: Springer.

Gedo, J. E., \& Goldberg, A. (1976). Models of the mind: A psychoanalytic theory: University of Chicago Press.

Gneezy, U., Niederle, M., \& Rustichini, A. (2003). Performance in Competitive Environments: Gender Differences. The quarterly journal of economics, 118(3), 1049-1074.

Gray, A. (2016). The 10 skills you need to thrive in Fourth Industrial Revolution. https://www.weforum.org/agenda/2016/01/the-10-skills-you-need-to-thrive-in-the-fourth-industrialrevolution/

Guilford, J. P. (1959). Three Faces of Intellect. American psychologist, 14(8), 469-479.

Gärtner, H. J. (1997). Kreativität im Chemieunterricht. [Creativity in Chemistry Lesson]. Naturwissenschaften im Unterricht, $8(12-20)$.

Gómez, M., Toma, R. B., Ortiz-Revilla, J., \& Merino, M. (2019). Creativity development through problem-based informal science. Paper presented at GIREP-ICPE-EPEC-MPTL CONFERENCE, Budapest, Hungary.

Hemdan, A. H., \& Kazem, A. M. (2019). Creativity Development of High-Achieving Students. Creativity Research Journal, 31(3), 296-308.

Howells, K. (2018). The future of education and skills: education 2030: the future we want. https://www.oecd.org/education/2030/E2030\%20Position\%20Paper\%20(05.04.2018).pdf

Hu, W., \& Adey, P. (2002). A Scientific Creativity Test for Secondary School Students. International Journal of Science Education, 24(4), 389-403. doi: 10.1080/09500690110098912

Janštová, V., Dvořáková, R., \& Jáč, M. (2016). Identiffing the factors that motivate pupils toward science competitions. Paper presented at the ESERA 2015 Conference. Science education research: Engaging learners for a suitable future, Helsinki, Finland.

Jo, S. M. (2009). A Study of Korean Students' Creativity in Science Using Structural Equation Modeling (Doctoral dissertation). https://repository.arizona.edu/handle/10150/193568

Kaufman, J. C., \& Beghetto, R. A. (2009). Beyond Big and Little: The Four C Model of Creativity. Review of general psychology, $13(1), 1-12$.

Kind, P. M., \& Kind, V. (2007). Creativity in Science Education: Perspectives and Challenges for Developing School Science. Studies in Science Education, 43, 1-37. doi: 10.1080/03057260708560225

Kohlberg, L. (1987). The development of moral judgment and moral action. In L. Kohlberg (Ed.) Child psychology and childhood education: A cognitive-developmental view, pp. 259 - 328. New York: Longman.

Lenofelder, A., \& Heller, K. A. (2002). German Olympiad Studies: Findings from a Retrospective Evaluation and from In-Depth Interviews: Where Have All the Gifted Females Gone. Journal of Research in Education, 12(1), 86-92.

Lopez, E. C., Esquivel, G. B., \& Houtz, J. C. (1993). The Creative Skills of Culturally and Linguistically Diverse Gifted Students. Creativity Research Journal, 6(4), 401-412. doi: 10.1080/10400419309534495

Miller, B. C., \& Gerard, D. (1979). Family Influences on the Development of Creativity in Children: An Integrative Review. Family Coordinator, 295-312.

Mohtar, L. E., Halim, L., \& Iksan, Z. H. (2016). Cognitive, Affective and Students' Achievemen in Physics: A Hypothetical Model for Structural Equation Modeling testing. Paper presented at the 4th International Conference on ASEAN Comparative Education Research Network (ACERN), Padang - West Sumatra.

Mund, W. (2007). Jugend forscht und Jugend musiziert: kognitive Fähigkeiten und Persönlichkeitsmerkmale erfolgreicher Teilnehmer. ['Jugend forscht' and 'Jugend musiziert': Cognitive Abilities and Personality Traits of Successful Participants.] (Doctoral dissertation). http://archiv.ub.uni-marburg.de/diss/z2008/0750/pdf/dwm.pdf

Niedersächisches Kultusministerium (Hrsg.). (2017). Kerncurriculum für das Gymnasium - gymnasiale Oberstufe. Chemie. https://db2.nibis.de/1db/cuvo/datei/ch_go_kc_druck_2017.pdf 
Niedersächsisches Kultusministerium (Hrsg.). (2012). Kerncurriculum für die integrierte Gesamtschule. Schuljahrgänge 5-10. Naturwissenschaften. https://db2.nibis.de/1db/cuvo/datei/kc_2012 igs_nws_i.pdf

Niedersächsisches Kultusministerium (Hrsg.). (2015). Kerncurriculum für das Gymnasium. Schuljahrgänge 5-10. Naturwissenschaften. https://db2.nibis.de/1db/cuvo/datei/nw gym si kc druck.pdf

Omusonga, T. O., Indoshi, F. C., \& Achieng'Rabari, J. (2011). Differences in Divergent Thinking among Secondary School Physics Students. Journal of Emerging Trends in Educational Research and Policy Studies, 2(4), 216-227.

Piske, F., Stoltz, T. , Camargo, D. , Vestena, C. , Machado, J. , de Freitas, S., Dias, C. \& Taucei, J. (2017). Creation Process during Learning of Gifted Students: Contributions from Jean Piaget. Creative Education, 8(4), 505-513. doi: https://doi.org/10.4236/ce.2017.84039.

Rosenblatt, E., \& Winner, E. (1988). The Art of Children's Drawing. Journal of Aesthetic Education, 22(1), 3-15. doi: $\underline{10.2307 / 3332960}$

Runco, M. A. (1986). Divergent Thinking and Creative Performance in Gifted and Nongifted Children. Educational and Psychological Measurement, 46(2), 375-384. doi: 10.1177/001316448604600211

Runco, M. A. (2014). Developmental Trends and Influences on Creativity. In: Runco, M. A. (Ed.), Creativity (Second edition, pp. 39 - 67): Academic Press. doi: 10.1016/B978-0-12-410512-6.00002-3

Runco, M. A., \& Albert, R. S. (1985). The Reliability and Validity of Ideational Originality in the Divergent Thinking of Academically Gifted and Nongifted Children. Educational and Psychological Measurement, 45(3), 483-501.

Runco, M. A., \& Jaeger, G. J. (2012). The Standard Definition of Creativity. Creativity research journal, 24(1), 92-96.

Runco, M. A., \& Okuda, S. M. (1988). Problem Discovery, Divergent Thinking, and the Creative Process. Journal of youth and adolescence, 17(3), 211-220. doi: 10.1007/BF01538162

Sahin, A. (2013). STEM Clubs and Science Fair Competitions: Effects on Post-Secondary Matriculation. Journal of STEM Education, 14(1), 5-11.

Sayed, E. M., \& Mohamed, A. H. H. (2013). Gender Differences in Divergent Thinking: Use of the Test of Creative Thinking-Drawing Production on an Egyptian Sample. Creativity Research Journal, 25(2), 222-227. doi: $\underline{10.1080 / 10400419.2013 .783760}$

Schwarz, J. (2020a). Mann-Whitney-U-Test. Methodenberatung Universität Zürich.

Schwarz, J. (2020b). Wilcoxon-Test. Methodenberatung der Universität Zürich.

Semmler, L., \& Pietzner, V. (2017). Creativity in Chemistry Class and in General-German Student Teachers' Views. Chemistry Education Research and Practice, 18(2), 310-328.

Smith, G., \& Carlsson, I. (1985). Creativity in Middle and Late School Years. International Journal of Behavioral Development, 8(3), 329-343.

Smolucha, L. W., \& Smolucha, F. C. (1985). A Fifth Piagetian Stage: The Collaboration Between Analogical and Logical Thinking in Artistic Creativity. Visual Arts Research, 90-99.

Starko, A. J. (2018). Creativity in the classroom: schools of curious delight. (6 ${ }^{\text {th }} \mathrm{Ed}$.). New York: Routledge, Taylor \& Francis.

Sternberg, R. J. (2018). What's Wrong with Creativity Testing? The Journal of Creative Behavior. doi: 10.1002/jocb.237

Torrance, E. P. (1966). Torrance tests of creative thinking: Norms-technical manual: Verbal tests, forms a and b: Figural tests, forms a and $b$. New York: Personal Press.

Torrance, E. P. (1968). A Longitudinal Examination of the Fourth Grade Slump in Creativity. Giffed Child Quarterly, 12(4), 195-199.

TU Braunschweig. (2020). Agnes-Pockels-Labor: Angebote. https:/ /www.tu-braunschweig.de/agnes-pockels-labor

Urban, K. K. (1991). On the Creativity Development in Children. Creativity Researcb Journal, 4, 177-191.

Urban, K. K. (2004). Kreativität: Herausforderung für Scbule, Wissenschaft und Gesellschaft. [Creativity. Challange for school, science and society.7. Münster: LIT Verlag.

Urban, K. K., \& Jellen, H. G. (1993). Test zum Schöpferischen Denken-Zeichnerisch (TSD-Z). Hannover: Universität Hannover, Arbeitsstelle HEFE.
Urban, K. K. (2011). Möglichkeiten und Grenzen von Kreativitätsdiagnostik. Ein programmatischer

Beitrag. [Possibilities and limits of creativity diagnostics. A programmatic contribution.]. In Karg-Stiftung (Ed.), (Vol. 2, p. 18-27). Frankfurt.

Wakefield, J. F. (1985). Towards creativity: Problem finding in a Divergent-Thinking Exercise. Child Study Journal.

Wallach, M. A., \& Kogan, N. (1965). Modes of thinking in young cbildren. New York: Holt, Rinehart, \& Winston.

Webb, N. M. (1984). Sex Differences in Interaction and Achievement in Cooperative Small Groups. Journal of educational psychology, 76(1), 33 .

Westby, E. L., \& Dawson, V. L. (1995). Creativity: Asset or Burden in the Classroom? Creativity Research Journal, 8(1), 110. Wirt, J. L. (2011). An Analysis of Science Olympiad Participants' Perceptions Regarding their Experience with the Science
and $\quad$ Engineering Academic Competition. (Doctoral dissertation). https://scholarship.shu.edu/cgi/viewcontent.cgiparticle $=1014 \&$ context=dissertations

Wu, W.-T., \& Chen, J. D. (1999). A Follow-Up Study of Taiwan Physics and Chemistry Olympians-the Environmental Influences. https://www.childresearch.net/projects/special/1999_01.html

ZARM. (2018). DroPS - Schülerexperimente unter Schwerelosigkeit. [DroPS - Students Experiments under Weightless.] https://www.zarm.uni-bremen.de/de/nachwuchs/drops-das-experiment-im-fallturm.html

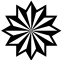

IJPCE - International Journal of Physics and Chemistry Education, 13(1), 1-11 